\title{
Manganese-Doping Effects on Magneto-Optical Properties of Terbium Borate Glass
}

\author{
Tomokatsu HAYAKAWA, Dai IMAIZUMI and Masayuki NOGAMI \\ Department of Materials Science and Engineering, Nagoya Institute of Technology, Gokiso-cho, Showa-ku, Nagoya-shi 466-8555
}

\author{
テルビウムホウ酸塩ガラスの磁気光学特性へのマンガン添加効果 \\ 早川知克·今泉 大·野上正行 \\ 名古屋工業大学材料工学科無機材料コース, 466-8555 名古屋市昭和区御器所町
}

\begin{abstract}
Dynamical Faraday rotation measurement with the high magnetic fields of $\sim 16 \mathrm{~T}$ has revealed the presence of microscopic magnetic coupling among trivalent terbium $\left(\mathrm{Tb}^{3+}\right)$ ions at low temperature in $\mathrm{Tb}_{2} \mathrm{O}_{3}$-riched borate glasses, caused by the superexchange interaction via oxygen ion. Doping by the divalent manganese $\left(\mathrm{Mn}^{2+}\right)$ ions into $\mathrm{Tb}_{2} \mathrm{O}_{3}-\mathrm{B}_{2} \mathrm{O}_{3}$ glass made the magnetic correlation temperature $\left(T_{\mathrm{MC}}\right)$ rising from 120 to $250 \mathrm{~K}$, due to the formation of stronger antiferromagnetic couplings between $\mathrm{Tb}^{3+}$ and $\mathrm{Mn}^{2+}$ ions. The repetitional application of the $16 \mathrm{~T}$-pulsed magnetic fields at lower temperature than $30 \mathrm{~K}$ destroyed the magnetic couplings so that the Faraday rotation could be enhanced. After the operations, the Faraday rotation curves at $300 \mathrm{~K}$ were drastically changed upon the incorporation of $\mathrm{Mn}^{2+}$ ions.
\end{abstract}

[Received March 12, 2002; Accepted August 9, 2002]

Key-words : Faraday rotation, Pulsed magnetic fields, Terbium ions, Divalent manganese ions, Magnetic fuctuation, Superexchange interaction, Antiferromagnetic couplings

\section{Introduction}

Faraday rotation glasses containing rare-earth ions ${ }^{1)-5)}$ possess an excellent transparency in the visible region, but their 'Verdet constants,' defined by Faraday angle $\theta_{\mathrm{F}}$ per a light-passing length $L$ per a unit of magnetic field $B$, are still smaller than those of infrared-active magnetic crystals (for instance, a yttrium iron garnet (YIG)). In the long-distance telecommunication established within an infrared optical window of silica-based fibers, such a transparent Faraday material in the infrared region is utilized for optical attenuaters and circulators. ${ }^{6), 7)}$ The successful establishment of the optical communication enables us to expect that in the near future the optical band used for information processing and/ or short-distance communication is required to be extended to the visible region. Hence, it should be considered how we obtain Faraday devices working in the corresponding wavelength region. Iron garnet films combined with several rare-earth elements, for example $\mathrm{Nd}-\mathrm{Lu}-\mathrm{Y}-\mathrm{IG},{ }^{8)}$ are in the candidates, which show a large Faraday rotation of $\sim 10^{3}$ degree $/ \mathrm{cm}$ in the range of $500-800 \mathrm{~nm}$, but are nonthermodynamical materials so as to have a limitation of their thickness $(\sim$ a few $\mu \mathrm{m})$. A family of paramagnetic terbium gallium/aluminum garnet (TGG/TAG) bulk crystals, ${ }^{9)-11 \text { ) }}$ which has a large Verdet constant of $-190 \mathrm{rad} . \mathrm{T}^{-1} \cdot \mathrm{m}^{-1}$ at $532 \mathrm{~nm}$, is also one of the candidates though they have an economical issue in production. On the other hand, rareearth oxide glasses with a high concentration of rare-earth content $(20-30 \mathrm{~mol} \%)$ are an easy and economical mass product, and possibly formed in fiber if needed. To best our knowledge, a largest Verdet constant among them was at most $-102.6 \mathrm{rad} . \mathrm{T}^{-1} \cdot \mathrm{m}^{-1}(=-0.353 \mathrm{~min} / \mathrm{Oe} / \mathrm{cm})$ for a $30 \mathrm{~Tb}_{2} \mathrm{O}_{3} \cdot 70 \mathrm{~B}_{2} \mathrm{O}_{3}$ glass. ${ }^{4}$ (As a conventional usage, min/ $\mathrm{Oe} / \mathrm{cm}$ is also used for Verdet constant. The following equation is helpful to the unit-conversion from cgs to MKS unitsystem: $1 \mathrm{~min} / \mathrm{Oe} / \mathrm{cm}=290.74 \mathrm{rad} . \mathrm{T}^{-1} \cdot \mathrm{m}^{-1}$ ) Thus, such Faraday rotation glasses still remain important as well.

To improve the Faraday rotation effect of rare-earth oxide glasses, there are mainly three strategies: The first is increasing the concentration of rare-earth ions in glasses. ${ }^{12}$ ) The second is how to introduce into glasses magnetic order- ings in microscopic viewpoints so that local magnetic fields, so-called molecular fields, at sites of magnetically interacting rare-earth ions in glasses might be enhanced. The last one is an increase in the covalency of the bond between rareearth ions and oxygen ions, which decreases the resonant frequency of Faraday rotation corresponding to the $f-d$ transition of rare-earth ions. ${ }^{13)}$ We give attention to the second one in which, by using a transition metal element, microscopic magnetic orderings in glasses are intensively introduced.

Divanent manganese $\left(\mathrm{Mn}^{2+}\right)$ ion is selected as a dopant because it has a large magnetic moment $(J=5 / 2)$ in the ground state and an expanded wave-function of half-filled $d$ electrons. Thus, it is expected to interact magnetically with a rare-earth ion in glasses. As a glass matrix we chose a terbium metaborate $\left(25 \mathrm{~Tb}_{2} \mathrm{O}_{3} \cdot 75 \mathrm{~B}_{2} \mathrm{O}_{3}\right)$ glass. This paper reports the presence of antiferromagnetic coupling among magnetic ions at low temperature in $\mathrm{Tb}_{2} \mathrm{O}_{3}-\mathrm{B}_{2} \mathrm{O}_{3}$ glasses with and without $\mathrm{Mn}^{2+}$ ions, studied in a dynamical Faraday rotation measurement. By doping $\mathrm{Mn}^{2+}$ ions into a terbium metaborate glass, the magnetic correlation temperature $\left(T_{\mathrm{MC}}\right)$ is increased from 120 to $250 \mathrm{~K}$. It will also be shown that high magnetic fields of $\sim 16 \mathrm{~T}$, which are able to induce magnetic uniaxial anisotropy even in amorphous materials of glasses, enhance the Faraday rotation at much lower temperature than its glass transition temperature $\left(T_{\mathrm{g}}\right)$ because of the modification of magnetic structures in glasses.

\section{Experiment}

Glasses used in this study contained approximately 25 mol\% $\mathrm{Tb}_{2} \mathrm{O}_{3}$ in the $\mathrm{B}_{2} \mathrm{O}_{3}$ matrix (BTb25) without and (MnBTb25) with $\mathrm{Mn}^{2+}$ ions. The batch-compositions $(\mathrm{mol} \%)$ of these glasses were $24.94 \mathrm{~Tb}_{2} \mathrm{O}_{3} \cdot 74.81 \mathrm{~B}_{2} \mathrm{O}_{3}$. $0.25 \mathrm{Sb}_{2} \mathrm{O}_{3}(\mathrm{BTb} 25)$ and $2.61 \mathrm{Mn}_{3} \mathrm{O}_{4} \cdot 24.29 \mathrm{~Tb}_{2} \mathrm{O}_{3} \cdot 72.86 \mathrm{~B}_{2} \mathrm{O}_{3}$. $0.24 \mathrm{Sb}_{2} \mathrm{O}_{3}$ (MnBTb25), respectively. Starting materials were $\mathrm{Tb}_{2} \mathrm{O}_{3}, \mathrm{H}_{3} \mathrm{BO}_{3}, \mathrm{Sb}_{2} \mathrm{O}_{3}$ and $\mathrm{Mn}\left(\mathrm{NO}_{3}\right)_{2} \cdot 6 \mathrm{H}_{2} \mathrm{O}$. The powder of $\mathrm{Tb}_{2} \mathrm{O}_{3}$ was obtained from commercially available $\mathrm{Tb}_{4} \mathrm{O}_{7}$ by heating at $800^{\circ} \mathrm{C}$ under flowing $\mathrm{H}_{2}$ gas. The mixture of $\mathrm{Tb}_{2} \mathrm{O}_{3}, \mathrm{H}_{3} \mathrm{BO}_{3}$ and $\mathrm{Sb}_{2} \mathrm{O}_{3}$ were melted for $1 \mathrm{~h}$ at $1200^{\circ} \mathrm{C}$ in an alumina crucible in air. After the melt-quench- 


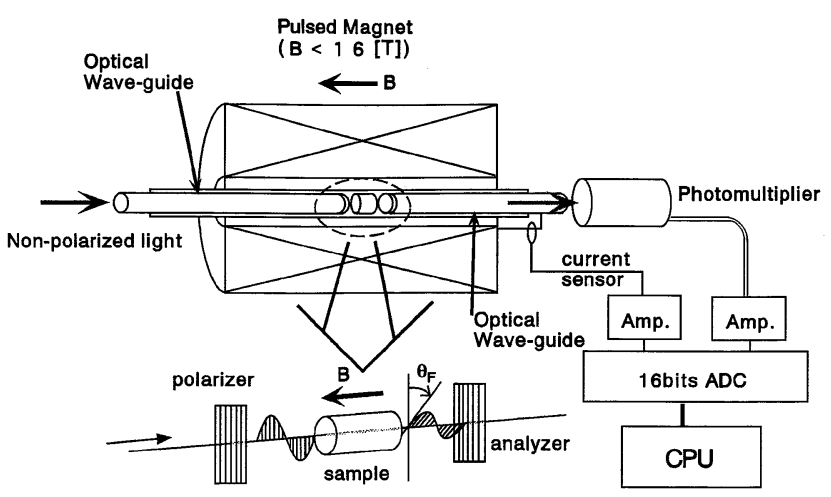

Fig. 1. Experimental setup of the dynamical Faraday rotation measurement.

ing on a graphite mold, the thermal treatment for annealing was taken at $600^{\circ} \mathrm{C}$ for 10 min to obtain BTb25 glass $\left(T_{\mathrm{g}}=\right.$ $770^{\circ} \mathrm{C}$ ). Furthermore, the glass was crushed into power and mixed with $\mathrm{Mn}\left(\mathrm{NO}_{3}\right)_{2} \cdot 6 \mathrm{H}_{2} \mathrm{O}$. In the same way as BTb25, the mixture was melted and quenched so as to obtain the terbium-borate glass incorporated with $\mathrm{Mn}_{3} \mathrm{O}_{4}$ ( $\left.\mathrm{MnBTb} 25\right)$ after annealing. To control valence state of $\mathrm{Mn}$ ions in the melt, niobium oxide $\left(\mathrm{Nb}_{2} \mathrm{O}_{5}\right)$ was also incorporated in the terbium borate glass, so that a $1.28 \mathrm{Mn}_{3} \mathrm{O}_{4} \cdot 2.59 \mathrm{Nb}_{2} \mathrm{O}_{5}$. $23.97 \mathrm{~Tb}_{2} \mathrm{O}_{3} \cdot 71.91 \mathrm{~B}_{2} \mathrm{O}_{3} \cdot 0.24 \mathrm{Sb}_{2} \mathrm{O}_{3}(\mathrm{MnNbBTb} 25)$ glass was obtained. Optical absorption spectra were observed with a ultraviolet-visible spectrophotometer (JASCO, Ubest V$570)$ to investigate valence states of manganese ions embedded in the borate glasses.

In this study, Faraday rotation measurements were carried out with pulsed magnetic fields in the temperature range over 15 to $\left.300 \mathrm{~K} .{ }^{14}\right)$ The pulsed magnetic field reached up to the maximum of $16 \mathrm{~T}$ in $13 \mathrm{~ms}$ and decreased to $0 \mathrm{~T}$ in $15 \mathrm{~ms}$. A He-Ne laser $(\lambda=632.8 \mathrm{~nm}$, random polarization) was used as a light source. The incident light was led into the sample through an optical wave-guide (fused silica; Toshiba Ceramics, T-1030). A film polarizer (Koyo, HN-32) in front of the sample changed the incident light into a linearly polarized light. A film analyzer in the rear of the sample isolated the transmission intensity depending on the rotation angle from the transmitted light, as shown in Fig. 1. The glasses were cut into a rod shape of $2 \mathrm{~mm}$ in diameter with $L=5 \mathrm{~mm}$. Both the bases of the rodshaped glasses were polished in optical flat for the Faraday rotation measurement. Orientation of the film polarizer and analyzer was inclined one another by several degrees $\theta_{0}$. With an increase in the density of magnetic fluxes penetrated into the sample, the intensity of the transmission was sinusoidally varied. The minimum points showed the Faraday angle $\theta_{\mathrm{F}}$ of $n \pi / 2+\theta_{0}(n$ : integer $)$ and the maximum the $\theta_{\mathrm{F}}$ of $n \pi+\theta_{0}$.

\section{Results}

Figure 2 shows absorption spectra of terbium borate glasses with and without manganese ions. The binary system of $\mathrm{Tb}_{2} \mathrm{O}_{3}-\mathrm{B}_{2} \mathrm{O}_{3}$ glass (BTb25) has a good transparency in the visible region, while the doped manganese ions contribute to optical absorption mainly in the region of 450-600 $\mathrm{nm}$ due to the spin-allowed ${ }^{5} E_{\mathrm{g}} \rightarrow{ }^{5} T_{2 \mathrm{~g}}$ transition of trivalent manganese $\left(\mathrm{Mn}^{3+}\right)$ ions. Divalent manganese $\left(\mathrm{Mn}^{2+}\right)$ ions exhibit an absorption peak around $415 \mathrm{~nm}\left({ }^{6} A_{1 \mathrm{~g}} \rightarrow{ }^{4} E_{\mathrm{g}},{ }^{4} A_{1 \mathrm{~g}}\right.$; spin-forbidden) when they are located in a disroted octahedral ligand. ${ }^{15)-18)}$ Because of the high concentration of - $\mathrm{Tb}_{2} \mathrm{O}_{3}$ content, the $f-f$ transitions such as ${ }^{7} F_{6}-{ }^{5} D_{4},{ }^{5} D_{3}$, and ${ }^{5} L_{10}$, are clearly observed. The samples investigated are

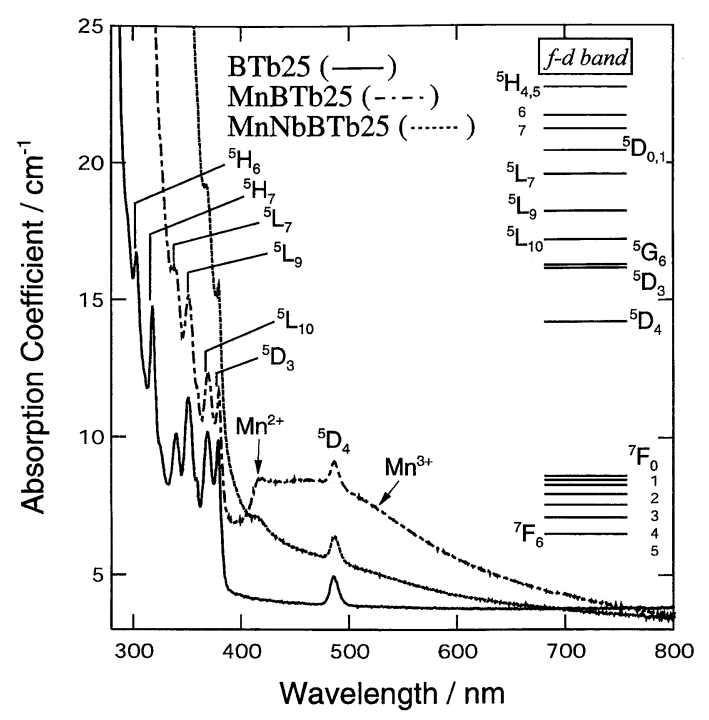

Fig. 2. Absorption spectra of BTb25, MnBTb25 and $\mathrm{MnNb}$ $\mathrm{BTb25}$. The energy scheme of $\mathrm{Tb}^{3+}$ ion is also illustrated.

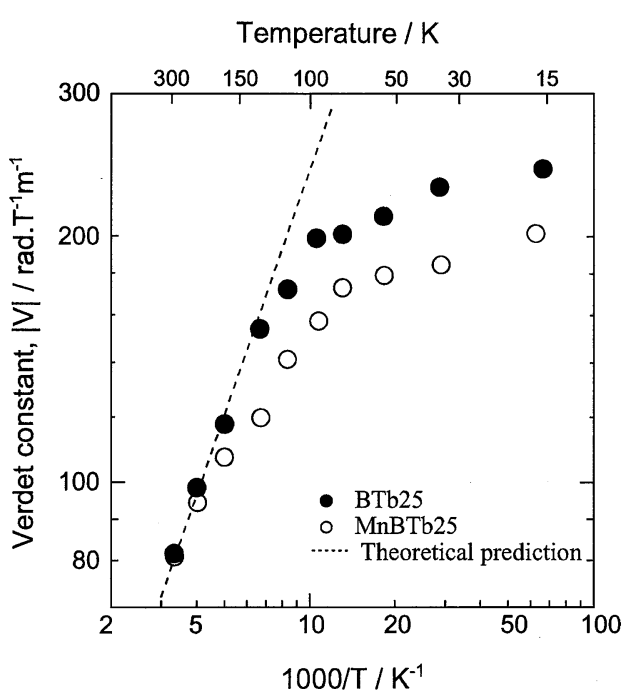

Fig. 3. Temperature-dependence of the Verdet constants (log$\log$ plot of $|V|$ vs. $1 / T)$ of BTb25 and MnBTb25 at $632.8 \mathrm{~nm}$.

paramagnetic in nature and have a negative sign for the Verdet constants. Figure 3 shows the temperature $T$-dependence of the Verdet constants (log-log plot of $|V|$ vs. $1 / T$ ) at $632.8 \mathrm{~nm}$ for BTb25 and MnBTb25. In the case of $\mathrm{BTb} 25$, the $1 / T$ dependency is found around room temperature. Below $120 \mathrm{~K}$, however, the Verdet constant of BTb25 has a tendency to be independent of the temperature, which is smaller than the theoretically predicted $1 / T$ line. ${ }^{19)}$ This indicates the formation of $\mathrm{Tb}^{3+}(\uparrow)-\mathrm{O}^{2-}-\mathrm{Tb}^{3+}(\downarrow)$ antiferromagnetic couplings ${ }^{20), 21)}$ owing to the superexchange interaction between $\mathrm{Tb}^{3+}$ ions in the glass, preventing magnetic moments of $\mathrm{Tb}^{3+}$ ions from orienting to the direction of magnetic fields. On the other hand, the Verdet constant of MnBTb25 has already exhibited a deviation from the theoretical prediction even below $200 \mathrm{~K}$. This shows that $\mathrm{MnBTb} 25$ for Faraday rotation is not completely paramagnetic at higher temperature than BTb25. It is because a stronger exchange interaction works between $\mathrm{Mn}^{2+}$ and 


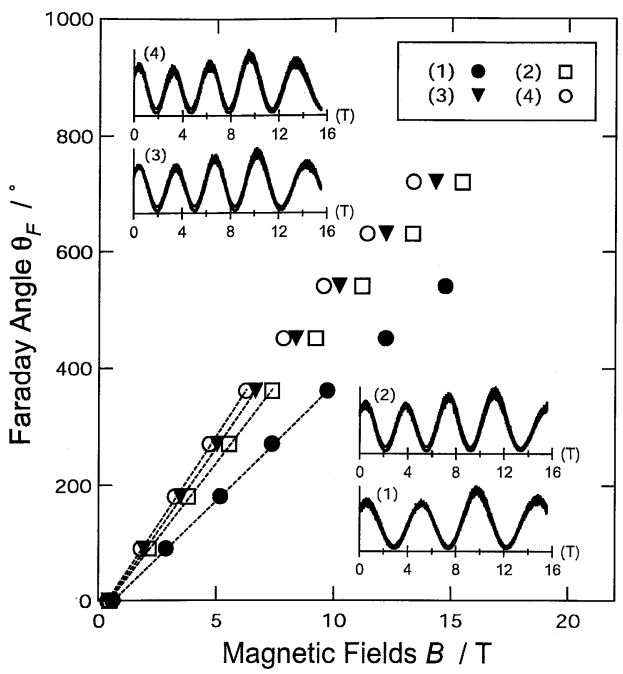

Fig. 4. $\theta_{\mathrm{F}}$ (Faraday angle) vs. $B$ (magnetic field) plots of the dynamical Faraday rotations for MnBTb25 at $15 \mathrm{~K}$. The insertions of the figure is Faraday rotation curves at $15 \mathrm{~K}$, in which the number in parenthesis shows the sequential number of the multiple-application of the 16T-magnetic fields.

Table 1. Verdet Constants $\left(\mathrm{rad} \cdot \mathrm{T}^{-1} \cdot \mathrm{m}^{-1}\right)$ at $632.8 \mathrm{~nm}$ at $15 \mathrm{~K}$ Against the Sequential Number of the Application of the 16T-Magnetic Field (Standard Deviation: $\pm 2 \mathrm{rad} . \mathrm{T}^{-1} \cdot \mathrm{m}^{-1}$ ). The Parenthesis Shows the Enhancement Ratio

\begin{tabular}{clll}
\hline \multirow{2}{*}{ Number } & \multicolumn{3}{c}{ Verdet constants, $|\mathrm{V}| /$ rad. $^{-1} \mathrm{~m}^{-1}$} \\
\cline { 2 - 4 } & BTb25 & MnBTb25 & MnNbBTb25 \\
\hline 1 & 238 & 144 & 229 \\
2 & $248(4.2 \%)$ & $190(31.9 \%)$ & $227(-0.9 \%)$ \\
3 & $256(7.6 \%)$ & $210(45.8 \%)$ & $226(-1.3 \%)$ \\
4 & $290(21.8 \%)$ & $223(54.9 \%)$ & $215(-6.1 \%)$ \\
\hline
\end{tabular}

$\mathrm{Tb}^{3+}$, which must tend to produce antiferromagnetic couplings in a similar way as in BTb25.

At lower temperature than $30 \mathrm{~K}$, it is observed that the repetitional application of high magnetic fields enhances the Faraday rotation effect for MnBTb25, as depicted in Fig. 4. On the first operation of the 16T-pulsed magnetic field, the number of maximum points is four (see (1) in the insertion of Fig. 4) and increases to five after the four-times operation (see (4) in the insertion of Fig. 4). The enhanced Faraday rotation results from the partial destruction of $\mathrm{Tb}^{3+} \mathrm{O}^{2-}-\mathrm{Tb}^{3+}$ or $\mathrm{Tb}^{3+} \mathrm{O}^{2-}-\mathrm{Mn}^{2+}$ antiferromagnetic couplings. Thus, the initial slope in $\theta_{\mathrm{F}}$ vs. $B$, in proportion to the 'Verdet constant', increases after each of the pulsed operations. The enhancement is also observed for BTb25 (see Table 1). The repetitional operations at the low temperature give rise to a significant change in Faraday rotation curves at $300 \mathrm{~K}$. Figure 5 (a) shows dynamical Faraday rotation curves at $300 \mathrm{~K}$ for MnBTb25 before and after the repetitional operations. In a weak field around $1 \mathrm{~T}$ the rapid response on the magneto-optical characteristics is obtained, while the slow rotation of the Faraday effect is observed in a strong field around $10 \mathrm{~T}$. The similar behavior is observed in $\mathrm{MnNbBTb25}$ (see Fig. 5(b)). On the other hand, the Faraday rotation at $300 \mathrm{~K}$ for non-doped terbium borate glass (BTb25) is not significantly changed (not shown (a) MnBTb25

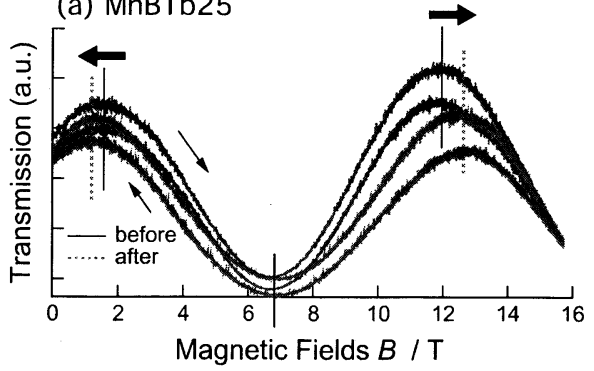

(b) MnNbBTb25

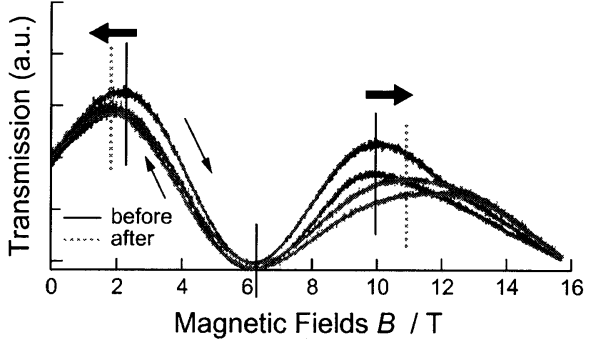

Fig. 5. Dynamical Faraday rotation curves at $300 \mathrm{~K}$ before and after the repetitional operations of the 16T-pulsed magnetic fields at $15 \mathrm{~K}$ for (a) MnBTb25 and (b) MnNbBTb25.

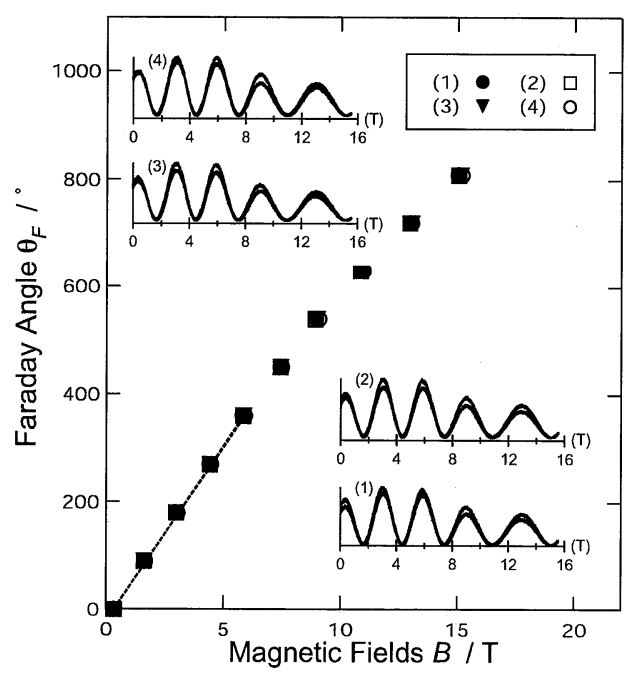

Fig. 6. $\theta_{\mathrm{F}}$ (Faraday angle) vs. $B$ (magnetic field) plots of the dynamical Faraday rotations for MnNbBTb25 at $15 \mathrm{~K}$. The insertions of the figure is Faraday rotation curves at $15 \mathrm{~K}$, in which the number in parenthesis shows the sequential number of the multiple-application of the 16T-magnetic fields.

here) after the repetitional operations at $15 \mathrm{~K}$. In addition, it is curious that $\mathrm{MnNbBTb} 25$ at the low temperature does not exhibit an enhancement of Faraday rotation by the repetitional application of the 16T-magnetic fields (see Fig. 6 and Table 1).

\section{Discussion}

On the prediction of the paramagnetic theory by Van Vleck and Hebb, ${ }^{19)}$ a Verdet constant $V$ for paramagnetic rotation is in proportion to the magnetic susceptibility $\chi$ and thus the inverse of absolute temperature $T$.

$$
V=\chi K /\left(\lambda^{2}-\lambda_{\mathrm{t}}^{2}\right)
$$

where $\lambda_{\mathrm{t}}$ is an effective wavelength of resonant transition 
and $K$ is a constant determined by the transition probability. Generally, a paramagnetic rotation due to rare-earth ions in glasses are caused by their $f-d$ transitions (oscillator strength: $\sim 10^{-2}$, which has $\sim 10^{4}$ times higher transition probability than $f-f$ transitions. ${ }^{22}$ ) The $f-d$ transition energy $\left(=c / \lambda_{t}\right)$ increases in a series of light rare-earth ions (Ce, $\operatorname{Pr}, \ldots .$.$) and takes a maximum in gadolinium (Gd) ion$ which corresponds to a half-filled $4 f$ electronic system. ${ }^{23)}$ As for the next rare-earth ion or $\mathrm{Tb}^{3+}$, the $f-d$ energy is lowered and the energy is increased again in a heavy rare-earth series $(\mathrm{Tb}, \mathrm{Dy}, \mathrm{Ho}, \ldots .$.$) . From the reasons of the relatively$ low $f-d$ energy and transparency, $\mathrm{Tb}^{3+}$ ion is a preferable magnetic ion for Faraday rotations in the visible region. As seen from Fig. 3, the highly-concentrated $\mathrm{Tb}_{2} \mathrm{O}_{3}$ oxide glass was paramagnetic around room temperature due to a week magnetic correlation between $\mathrm{Tb}^{3+}$ ions. It was below $100 \mathrm{~K}$ that the magnetic correlation between $\mathrm{Tb}^{3+}$ ions was observed. On the contrary, $\mathrm{Mn}^{2+}$ ions have a large magnetic moment $(J=5 / 2)$ and their wave function of $3 d^{5}$ electron is extended to neighboring oxygen ions. The incorporation of $\mathrm{Mn}^{2+}$ ions hence resulted in an increase in a magnetic correlation temperature $\left(T_{\mathrm{MC}}\right)$ from 120 to $250 \mathrm{~K}$, as shown in Fig. 3. Below the $T_{\mathrm{MC}}$ the magnetic couplings in $\mathrm{Tb}^{3+}$ $\mathrm{Tb}^{3+}$ and/or $\mathrm{Tb}^{3+}-\mathrm{Mn}^{2+}$ via oxygen ion occurred. It should be noticed that the magneto-optical properties of rare-earth ions in glasses, as mentioned in the first part of this section, were dependent upon how much their magnetic moments were oriented in the direction of the passing light beam because in the present experiment a Faraday configuration was utilized, where magnetic fields were applied in the direction of the light beam. The presence of the microscopic magnetic ordering produced at lower temperature due to the ion-ion interaction gave an influence to the Faraday rotation characteristics, eventually resulting in the deviation from the behavior of paramagnetism. Especially, since the response of the ion in magnetic coupling was considered to be different from that of a free ion without magnetic correlation, a rapid rise $(\sim 30 \mathrm{~ms})$ of the pulsed magnetic fields could sensitively detect the magnetic couplings in glasses.

Here we would like to emphasize that the presence of microscopic antiferromagnetic couplings does not necessarily lead to the Curie-Weiss low $\chi^{-1}=C(T-\Theta)$ and negative $\Theta$. To understand that, it is helpful to review the classical theory of antiferromagnetism using the concept of molecular fields, ${ }^{24), 25)}$ where every magnetic ion in sublattice is interacted with neighboring magnetic ions and all the contributions to the ion is modeled as 'molecular fields' (that is, a kind of effective medium approximations). For antiferromagnetism magnetic moments in each sublattice feel molecular fields in the opposite direction. On the assumption, the statistical calculation of the magnetization $M$ takes place so as to derive the Curie-Weiss law from $\mathrm{d} M / \mathrm{d} H$. Although this does not explain the origin of the magnetic interaction, the success of the theoretical explanation on the temperature-dependence of the magnetization is meaningful. One has to pay a special attention to an important assumption; "it is valid every time that all interactions from a surrounding to any magnetic ion in solids is expressed using the concept of effective medium approximation," which is directly related to the essence of the appearance of negative $\Theta$.

If an exchange interaction for a magnetic ion which is received from neighboring magnetic ions, to form a pair of magnetically coupled ions or a magnetic cluster consisting of some of magnetic ions, can not be regarded as an influence of a typical effective medium, the above-mentioned assumption should become invalid. This shows a possibility of keeping a paramagnetic behavior ( $1 / T$-dependence) even though magnetically-coupled ions are present, as long as the system is not approach an ordered state of antiferromagnetism when the temperature is decreasing. In fact, the magnetization of such highly-terbium oxide concentrated glasses obeys the $1 / T$ law down to a few decimal K. ${ }^{20), 26)}$ In Satos' experiment ${ }^{26)}$ where a vibrational sample magnetization (VSM) method was used, the magnetization characteristics around $3.0 \mathrm{~T}$ and $1.0 \times 10^{-3} \mathrm{~T}$ was interestingly different in case of high terbium concentration. However, by fitting the data of magnetic susceptibility with Curie-Weiss law the result of $\Theta=-0.7 \mathrm{~K}$ was obtained, which is regarded to be almost paramagnetic.

As shown in Table 1 and Fig. 4 it was observed that the high magnetic field of $16 \mathrm{~T}$ could destroy these magnetic couplings and the Faraday rotation effect drastically enhanced with the repetitional operations of the $16 \mathrm{~T}$-pulsed magnetic fields. Interestingly, after the destruction of magnetic couplings the Faraday rotation at $300 \mathrm{~K}$ was significantly changed in the $\mathrm{Mn}^{2+}$-modified $\mathrm{Tb}_{2} \mathrm{O}_{3}-\mathrm{B}_{2} \mathrm{O}_{3}$ system, as seen in Fig. 5(a). On the other hand, the binary $\mathrm{Tb}_{2} \mathrm{O}_{3}-\mathrm{B}_{2} \mathrm{O}_{3}$ system was not influenced, i.e. the Faraday rotation curve at $300 \mathrm{~K}$ was reproducible even after the operations at $15 \mathrm{~K}$. It is well-known that a magnetization of a bulk material in a strong magnetic field brings about an external stress ('Maxwell stress') imposed on the bulk. If the material is paramagnetic $(\chi>0)$ an expansion occurs and if diamagnetic $(\chi<0)$ a compression takes place. ${ }^{27)}$ Classical electromagnetic theory tells us the expression for the force,

$$
F_{1 \rightarrow 2}=1 / 2\left(\mu_{1}-\mu_{2}\right)\left(B / \mu_{0}\right)^{2}
$$

( $\mu_{0}$ : transmittance in vacuum) in a boundary between regions with transmittances of $\mu_{1}$ and $\mu_{2}$. Since the $\mathrm{Tb}_{2} \mathrm{O}_{3}-$ $\mathrm{B}_{2} \mathrm{O}_{3}$ binary system (BTb25) has a magnetic susceptibility of $\sim 10^{-2}$ at $15 \mathrm{~K}$, the expansion is roughly estimated to be $\sim 1 \mathrm{M} \mathrm{Pa}(\sim 10$ bar $)$ on the side plane of the rod-shaped sample. Generally, borate glasses is quite plastic in comparison with silica and silicate glasses, $\left.{ }^{28)}, 29\right)$ so that the large external stress by the pulsed magnetic fields might give rise to the displacement of glass constituents and consequently the destruction of the magnetic couplings among $\mathrm{Tb}^{3+}$ and $\mathrm{Mn}^{2+}$ ions. In the case that $\mathrm{Mn}^{2+}$ ions was incorporated in terbium borate glasses, a little displacement of $\mathrm{Mn}^{2+}$ ions greatly influenced the Faraday rotation of $\mathrm{Tb}^{3+}$ ions, (socalled 'magnetic fluctuation'). Here the role of the divalent state of $\mathrm{Mn}$ ion should be stressed because MnNbBTb25 had a similar behavior on the Faraday rotation at $300 \mathrm{~K}$ (see Fig. 5(b)), where the valence state of $\mathrm{Mn}$ ions was controlled in divalent state by the redox reaction of $\mathrm{Mn}$ and $\mathrm{Nb}$ ions in melt. However, there is the intrinsic difference between MnBTb25 and MnNbBTb25 in the low temperature behavior of Faraday rotation under the repetitional operations with the 16T-pulsed magnetic fields (compare Figs. 4 and 6). It is known that the binary system of $25 \mathrm{~Tb}_{2} \mathrm{O}_{3}$. $75 \mathrm{~B}_{2} \mathrm{O}_{3}$ glass is composed with double chains of three- and four-coordinated borons, which are inter-linked by $\mathrm{Tb}^{3+}$ ions. ${ }^{30)}$ Namely, the glass is essentially a two-dimensional (2D) system spooled like a thread ball and is supposed to be quite soft. $\mathrm{Nb}$ ions play a role of a network former in the $\mathrm{Tb}_{2} \mathrm{O}_{3}-\mathrm{B}_{2} \mathrm{O}_{3}$ system, ${ }^{31}$ ) which are covalently bonded with two double chains so as to form a three-dimensional (3D) stiff network. From the reasons, the enhancement of Faraday rotation at the low temperature with the destruction of $\mathrm{Tb}^{3+}-\mathrm{O}-\mathrm{Tb}^{3+}\left(\mathrm{Mn}^{2+}\right)$ magnetic couplings needed the softness of glass matrix. Moreover, in the binary $\mathrm{Tb}_{2} \mathrm{O}_{3}-$ $\mathrm{B}_{2} \mathrm{O}_{3}$ system, the shielding effect of $4 f^{8}$ electrons by outer shells of $5 s^{2} 5 p^{6}$ in $\mathrm{Tb}^{3+}$ eliminated the influence on the magnetic interactions among $\mathrm{Tb}^{3+}$ at $300 \mathrm{~K}$ even with the displacement of glass constituents. In this sense it can also be concluded that the $25 \mathrm{~Tb}_{2} \mathrm{O}_{3} \cdot 75 \mathrm{~B}_{2} \mathrm{O}_{3}$ glass is completely paramagnetic without a magnetic fluctuation. 


\section{Conclusion}

This study presented the effect of the modification with $\mathrm{Mn}^{2+}$ ions on the Faraday rotation in $\mathrm{Tb}_{2} \mathrm{O}_{3}-\mathrm{B}_{2} \mathrm{O}_{3}$ glasses. The superexchange couplings of $\mathrm{Tb}^{3+}(\uparrow) \mathrm{O}^{2-}-\mathrm{Tb}^{3+}(\downarrow)$ and $\mathrm{Tb}^{3+}(\uparrow) \mathrm{O}^{2-}-\mathrm{Mn}^{2+}(\downarrow)$ were magneto-optically observed at temperature below 120 and $250 \mathrm{~K}$ in $\mathrm{Tb}_{2} \mathrm{O}_{3}-\mathrm{B}_{2} \mathrm{O}_{3}$ glasses with and without $\mathrm{Mn}^{2+}$ ions, respectively. The repetitional application of the $16 \mathrm{~T}$-pulsed magnetic fields at $15 \mathrm{~K}$ destroyed the antiferromagnetic couplings in part and by heating up to $300 \mathrm{~K}$ a new magnetic coupling between $\mathrm{Tb}^{3+}$ and $\mathrm{Mn}^{2+}$ was created. This meant that the magnetic structure in the glass was modified by the incorporated $\mathrm{Mn}^{2+}$ ions at much lower temperature than $T_{\mathrm{g}}$.

Acknowledgement This work is partially supported by Research Foundation for the Electrotechnology of Chubu (REFEC).

\section{References}

1) Asahara, Y., J. Ceram. Soc. Japan, 99, 903-11 (1991).

2) MacFarlane, D. R., Bradbury, C. R., Newman, P. J. and Javorniczky, J., J. Non-Cryst. Solids, 213 \& 214, 199-204 (1997).

3) Shafer, M. W. and Suits, J. C., J. Am. Ceram. Soc., 49, 261-64 (1966).

4) Tanaka, K., Hirao, K. and Soga, N., Jpn. J. Appl. Phys., 34, 4825-26 (1995).

5) Qui, J., Tanaka, K. and Hirao, K., J. Am. Ceram. Soc., 80, 2696-98 (1997)

6) Wilson, D. K., Laser Focus, 24, 103-04 (1988).

7) Ballato, J. and Snitzer, E., Appl. Opt., 34, 6848-54 (1995).

8) Adachi, N., Hibi, T. and Okuda, T., J. Mag. Mag. Mater. 177-181, 233-34 (1998).

9) Chani, V. I., Yoshikawa, A., Machida, H., Satoh, T. and Fukuda, T., J. Cryst. Growth, 210, 663-69 (2000).

10) Yoshikawa, A., Kagamitani, Y., Pawlak, D. A., Sato, H., Machida, H. and Fukuda, T., Mater. Res. Bull., 37, 1-10 (2002).

11) Chani, V. I., Yoshikawa, A., Machida, H. and Fukuda, T., J. Cryst. Growth, 212, 469-75 (2000).
12) Hayakawa, T., Nogami, M., Nishi, N. and Sawanobori, N., Chem. Mater. 14, 3220-22 (2002).

13) Ebendorff-Heidepriem, H. and Ehrt, D., J. Non-Cryst. Solids, 248, 247-52 (1999)

14) Hayakawa, T. and Nogami, M., Solid State Commun., 116, 77-82 (2000).

15) Bingham, K. and Parke, S., Phys. Chem. Glasses, 6, 224-32 (1965).

16) Park, S., Bingham, K. and Watson, A. I., Phys. Chem. Glasses, 11, 223-24 (1970).

17) Gnappi, G., Montenero, A., Giori, D. C. and Schianchi, G., Mater. Chem. Phys., 23, 422-32 (1989).

18) Die, A. V., Leenaers, A. C. H. I., Blasse, G. and Van der Weg, W. F., J. Non-Cryst. Solids, 99, 32-44 (1988).

19) Van Vleck, J. H. and Hebb, M. H., Phys. Rev., 46, 17-32 (1934).

20) Hayakawa, T., Sato, K., Yamada, K., Kamata, N., Nishi, N. and Maruyama, F., Synth. Met., 91, 355-56 (1997).

21) Mendiratta, S. K., Costa, L. C. and De Sousa, E. G., J. Mater. Sci. Lett., 9, 301-03 (1990).

22) Wybourn, B. G., "Spectroscopic Properties of Rare Earths," Interscience (1965) pp. 83-96.

23) Loh, E., Phys. Rev., 147, 332-35 (1966).

24) Nagamiya, T., Yoshida, K. and Kubo, R., Adv. Phys., Phil. Mag., Supplement 4, 1 (1955).

25) Nagamiya, T. "Jisei no Riron," Yoshioka-Shoten, Tokyo (1988) pp. 38-51 [in Japanese].

26) Sato, K., Yamaguchi, K., Maruyama, F. and Nishi, N., Phys. Rev. B, 63, 104416-21 (2001).

27) Jackson, D. J., "Classical Electrodynamics," 2 nd ed., John Wiley \& Sons, New York, Chichester, Brisbane, Toronto, Singapore (1962) pp. 209-68.

28) Mackenzie, J. D., J. Am. Ceram. Soc., 46, 461-70 (1963)

29) Bridgman, P. W. and Simon, I., J. Appl. Phys., 24, 405-13 (1953).

30) Chakraborty, I. N., Day, D. E., Lapp, J. C. and Shelby, J. E., J. Am. Ceram. Soc., 68, 368-71 (1985).

31) Zhongcai, W., Bingkai, S. and Shizhuo, W., J. Non-Cryst. Solids, 80, 160-66 (1986). 